\title{
THE RESULTS OF CONSERVATIVE APPROACHES FOR PULMONARY HYDATID CYSTS.
}

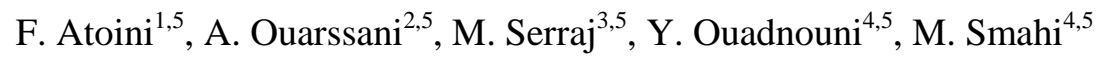 \\ ${ }^{1}$ Thoracic Surgery Department, My Ismail Military Hospital, Meknes, Morocco. \\ ${ }^{2}$ Pulmonology Department, My Ismail Military Hospital, Meknes, Morocco. \\ ${ }^{3}$ Pulmonology Department. Hassan II ${ }^{\mathrm{d}}$ University Hospital, Fes, Morocco. \\ ${ }^{4}$ Thoracic Surgery Department. Hassan II ${ }^{\mathrm{d}}$ University Hospital, Fes, Morocco. \\ ${ }^{5}$ Medical School of Fes, Sidi Mohamed Ben Abdellah University, Fez, Morocco.
}

\section{ABSTRACT}

Pulmonary hydatid cysts remains a public health problem in Morocco. We present the results of the conservative methods for treating the pulmonary hydatid cysts in 56 patients including the giants forms $(\geq 10 \mathrm{~cm})$ and the complicated cases. 71 cystectomies, one pericystectomy and one wegde resection realized by thoracotomy. There were 33 menand 23 women. The median age was 25 years old[8-64]. The lower lobes were affected in $72 \%$. Hepatic cysts were associated in 13 patients (23\%). The median duration of postoperative drainage was 6 days (range 2-48 days) and the median duration of hospitalization was 9 days (range 5-28 months). The median duration of follow-up was 15 months (range 3-46 months). Univariate analysis did not reveal significance when we compared the postoperative course according to the localizations on the lungs, the nature of the cysts, the presence of infection and the size of cysts. The conservative approaches, mainly cystectomies area safe and effective method for lung hydatid cysts, if the closure of the bronchial fistulas is well performed, that the capitonnage is adapted to the size of the residual cavity, and its location in the lung to avoid bronchial torsion and deformation. We suggest this technique for the management of lung hydatid cysts, outside the cases of significant destroyed pulmonary parenchyma mainly thus located on the middle lobe. We believe that lobectomy must be taken very carefully, mainly in infant and the older patients.

Keywords: Cystectomy, Hydatid Cyst, Lung, Pulmunary, Results, Surgery.

\section{Corresponding Author:}

Dr.Fouad Atoini, MD.

Address: Thoracic Surgery Department, My Ismail Military Hospital, Meknes, Morocco.

E- mail:f.atoini@gmail.com

Copyright (C) 2012- 2016 Dr Fouad Atoini and al. This is an open access article published under Creative Commons Attribution -Non Commercial- No Derives 4.0 International Public License (CC BY-NC-ND). This license allows others to download the articles and share them with others as long as they credit you, but they can't change them in any way or use them commercially.

\section{INTRODUCTION}

Hydatid cysts are frequent in Morocco who remains an endemic area for hydatidosis because of frequent sheep breeding; This disease is endemic in many part of the world, particularly the Mediterranean countries, central Asia including the Tibetan plateau, Northern and Eastern Africa, and South America [1,2]. Lungs represent the second location $(10-30 \%)$ of hydatidosis after the liver (50-60\%) $(3,4)$. The cysts occurs mainly on the lower lobes particularly on the right side (1-4).Usually these cysts increase progressively in size and cause complications on the lung like bronchial rupture and destroying parenchyma, when the chronic infection remains without diagnosis of the hydatid cyst. The diagnosis of pulmonary hydatid cystsis given according to the clinical symptoms, the radiological features and serological results. There are varieties of clinical forms of the pulmonary hydatid cysts, and sometimes different diagnosis are discussed mainly the pulmonary neoplasm or other infection like tuberculosis or aspergilloma.

Surgery represents the radical treatment for pulmonary hydatid cysts. The conservative methods preserving parenchyma (cystectomy, enucleation, peri-cystectomy) constitute the main techniques. Among these techniques, cystectomy represents the main procedure. Pulmonary resection is mainly indicated when pulmonary parenchyma is destroyed (1-5). Otherwise, the actual limits of the conservative approaches are always debated in the literature. There are no clear recommendations about the indication of pulmonary resection. In our 
practice, cystectomy represents the main technique used for surgery of pulmonary hydatid cysts. Our study analyze the outcomes after conservative approaches. The aim of this study was to define the determinants of outcome for a heterogeneous group of pulmonary hydatid cysts operated in our department.

\section{PATIENTS AND METHODS}

Our study is a retrospective cohort including 56 patients treated for lung hydatid cysts, between October 2010 and November 2016.Regardless of clinical forms of the pulmonary hydatid cysts including the nature and size of the lesion, the number and the type of bronchial fistulas, 71 cystectomies, 1 perikystectomy and 1 wedge resectionwere performedfor all the cysts by 60 thoracotomies (4 bilateral forms). The patients were monitoredon the immediate postoperative period, and after a median follow-up of 15 months (range 3-46 months).

\section{Operative technique:}

All approaches were performed under general anesthesia mainly with double-lumen endo-tracheal tube. The surgical approach was thoracotomy by the fifth or the sixth inter-costal space. In the cases of giant cysts, the inter-costal space was opened carefully to avoid its perforation.

Cystectomy consisted firstly of pulmonary liberation by a careful section of the fibrous bridges. The second step consisted of the protection of the operative field by compresses soaked in oxygenated water. If the cyst was intact, a small incision was performed in the most superficial point of the cyst; the aspiration of the fluid was accomplished directly to the aspirator though a suction cannula. For all cases, the cystic wall was incised on its largest diameter, and we removed the cystic membranes by forceps. We cleaned the residual cavity with gauzes that was saturated by povidone-iodine solution.

In order to visualize the bronchial fistulas, we filled the cavity by physiologic serum during pulmonary inflation. The bronchial fistulaswere closed by sutures with different forms according to their situations on the cavity, we usually used an absorbable wire (polyglatine $3 / 0$ or $2 / 0$ ). We performed capitonnagewhatever the size of the cavity. This procedure was adapted according to the localization and the form of cavity to avoid deformation of the lobe (horizontally, vertically or in oblique direction) (Figure 1).

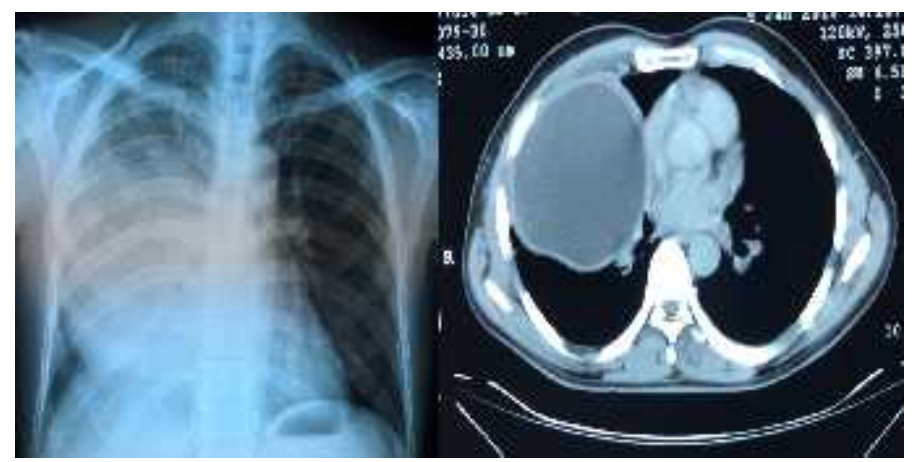

Figure 1: Chest X-ray and CT scan showing a giant lung hydatid cyst $(13 \mathrm{~cm})$ localized on the right lower lobe

Peri-cystectomy consists of excision of hydatid cyst along with the pericyst, which firmly adheres to normal lung parenchyma. Closure of the airway openings and approximation of the healthy lung parenchyma was mandatory.

Wedge resection consisted on resection on the peripheral part of the lobe with staplers including the cyst on the resection.

\section{Methods and statistical analysis:}

The data were collected from medical records, it has includes age, gender, symptoms, images findings of the cysts (location, number, size, intact or ruptured), postoperative drainage (number of chest tube and duration), hospital stay of patients and the data of follow-up.

According to the presence or not of complications, and the degree of pulmonary expansion for each patient, the results of follow-up were divided into three groups according to the postoperative period,first in the immediate postoperative course, then up to 1 month, between 1 month and 3 months, 
between 3 months and 6 months, and after 6 months of follow-up. Group 1 included the patients without postoperative complications, absence of clinical signs, and with good pulmonary expansion. Group 2: the patients without symptoms, but with minor radiological sequels, and group 3 included the patients with postoperative complications with symptoms, major radiological sequels with bad pulmonary expansion. We have defined complications in minor and major. Major complications included anomalies that necessitate specific therapy like pneumothorax, lobar or lung atelectasis, pneumonia and air leaks for up to 7 days in the postoperative. Minor complications included infra-lobaratelectasis, low pleural effusion or postoperative opacity on the level of the residual cavity with or without hydro-aeric level. The Epiinfo 7 software was used for the statistical analysis. The exact Fischer test was used for the comparison, test was considered significant if $\mathrm{p}$ was less than 0.05 .

\section{RESULTS}

The median age of the 56 patients was 25 years (range 8-64 years), less than $25 \%$ of patients were under 16 years. Men were $59 \%(n=33)$ and women $41 \%(n=23)$.

Symptoms were presents in $91 \%$; with pain in $53 \%$, dyspnea in $22 \%$, hemoptysis in $33 \%$, hydatid vomit in $33 \%$, and fever in $31 \%$. Five patients were asymptomatic at the time of diagnosis. Imaging exams (chest radiograph and chest CT scan) showed cysts on the right side in $54 \%(n=30)$, on the left side in $39 \%(\mathrm{n}=22)$ and bilateral in four cases $(7 \%)$. The lower lobes were involved in $72 \%$ $(n=43)$, and the other lobes in 28\% $(n=17)$ (Table I). The cysts were intact in $47 \% \quad(\mathrm{n}=28)$, and complicated by bronchial rupture in $53 \%(n=32)$, there are no cases of rupture in the pleura.

Table I. Localizations of the hydatid cysts on the pulmonary lobes.

\begin{tabular}{lll}
\hline Lobes & Number & Percentage \\
\hline Right upper & 6 & $10 \%$ \\
Middle & 2 & $3,3 \%$ \\
Right lower & 23 & $38,3 \%$ \\
Left upper & 6 & $10 \%$ \\
Left lower & 20 & $33,3 \%$ \\
Two lobes: & 3 & $5 \%$ \\
RUL and RLL & 2 & \\
RLL and ML & 1 & $100 \%$ \\
\hline Total & 60 &
\end{tabular}

The pulmonary cysts were associated with hepatic hydatid cysts in 13 cases (23\%), and with a mediastinal localization in one case. Five cases of the hepatic cysts were treated in the same operative time by phrenotomy.
The median size of cysts was $8 \mathrm{~cm}$ (range 4-22 cm), $27 \%(\mathrm{n}=16)$ were giant $(\geq 10 \mathrm{~cm})$ (figure 1) with a mean size of $13 \mathrm{~cm}$ (Table II). Among these cysts, $60 \%(n=36)$ has been infected. Chest X-ray and CT-scan illustrating different imaging features of the cysts are presented on the Figures (2-4).

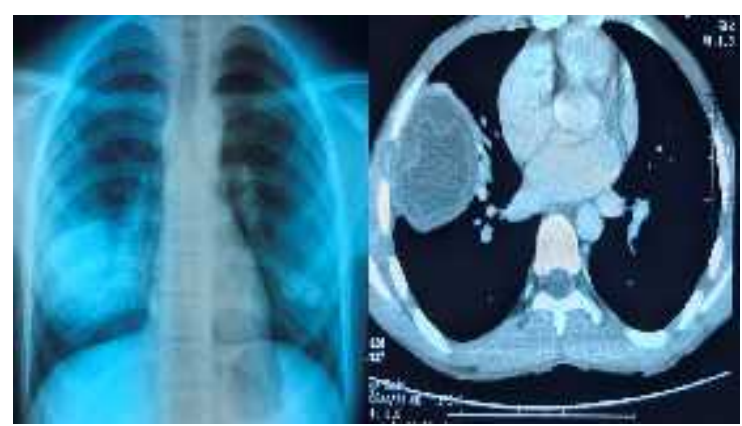

Figure 2: Chest X-ray and CT-scan of a $7 \mathrm{~cm}$ hydatid cyst of the middle lobe with visualization of the germinative membrane. 


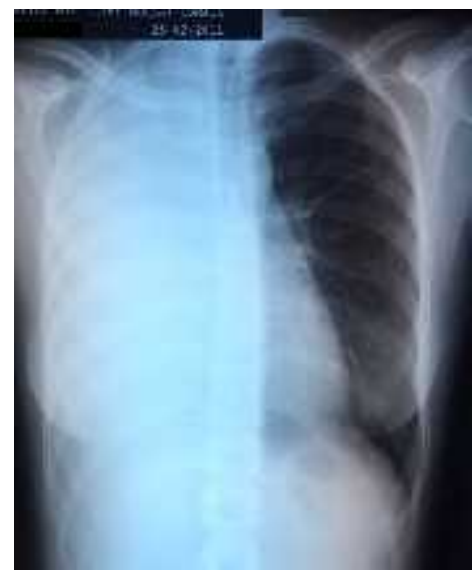

Figure 3: Chest X-ray showing a large opacity like pleuresis, it was a very giant hydatid cyst measuring $22 \mathrm{~cm}$
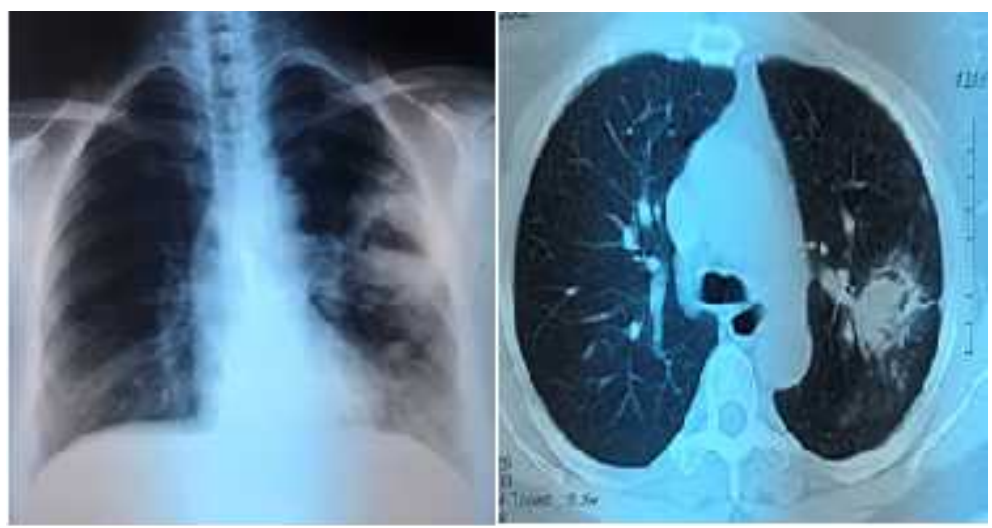

Figure 4: Chest X-ray and CT-scan showing a ruptured hydatid cyst of the left lower lobe

Table II. Size of the cysts according to the localization on the lung.

\begin{tabular}{|c|c|c|c|c|c|c|c|}
\hline & n (\%) & RUL & ML & RLL & LUL & LLL & BILOBAR \\
\hline$<5 \mathrm{~cm}$ & $9(15 \%)$ & 0 & 1 & 2 & 1 & 4 & $\begin{array}{l}1 \\
\text { RLL and ML }\end{array}$ \\
\hline $5.9 \mathrm{~cm}$ & $35(58 \%)$ & 3 & 0 & 15 & 4 & 12 & $\begin{array}{l}1 \\
\text { RUL and RLL }\end{array}$ \\
\hline$\geq 10 \mathrm{~cm}$ & $16(27 \%)$ & 3 & 1 & 6 & 1 & 4 & $\begin{array}{l}1 \\
\text { RUL and RLL }\end{array}$ \\
\hline
\end{tabular}

Among this73 cysts, it was a single cyst in 49 thoracotomies. Two cysts in nine thoracotomies and three cysts in two thoracotomies, in this cases we have considered the largest size of the cysts to define size in this study. After cystectomy, the chest cavity was drained by one chest tube in $80 \%$ $(n=48)$, and in $20 \%(n=12)$ by two chest tubes. The median duration of drainage was 6 days (range 2-48 days), and the median duration of hospitalization was 9 days (range 5-28 days).

The median duration of follow-up was 15 months (range 3-46 months). Postoperative outcomes were divided into three groups depending on the postoperative period (Table III). Two cases of pneumothorax were managed by chest tube drainage in one and in the other by conservative approach. The prolonged parenchymal air leaks were treated with chest physiotherapy and chest tube drainage. The lobar atelectasis occurring in two cases were resolved by fibroscopic aspiration. The use of antibiotics treated the cases of pneumonia. No recurrences were seen during follow-up.

Albendazole therapy was given to24 patients (43\%) postoperatively. It was administered at $12 \mathrm{mg} / \mathrm{kg} / \mathrm{day}$; the treatment was undertaken for 4 cycles (three months) of 3 weeks with pause interval two weeks with control of the blood count and the liver tests. Only one patient had elevated 
test results during the course after 3 cycles, we stopped then the treatment.

Table III. Description of the postoperative outcomes regarding follow-up.

\begin{tabular}{|c|c|c|c|c|c|c|}
\hline & \multicolumn{2}{|l|}{ Major } & \multicolumn{2}{|l|}{ Minor } & \multirow{2}{*}{$\begin{array}{l}\text { Normal } \\
\text { (n) }\end{array}$} & \multirow{2}{*}{ Total } \\
\hline & Description & $\mathrm{n}$ & Description & $\mathrm{n}$ & & \\
\hline \multirow[t]{5}{*}{ Immediate } & Pneumothorax & 2 & Pleural effusion & 1 & 44 & 60 \\
\hline & Pneumonia & 2 & Atelectasis & 11 & & \\
\hline & Air leak & 3 & Hydroaeric level in the residual cavity & 1 & & \\
\hline & Atelectasis & 2 & Surrelevation of the diaphragmatic cupola & & & \\
\hline & & & Postoperative opacity & 3 & & \\
\hline \multirow[t]{2}{*}{ Up to 1 month } & Pneumothorax & 2 & Persistent atelectasis & 8 & 46 & 60 \\
\hline & & & Persistent cavity & 4 & & \\
\hline $1-3$ months & 0 & & Persistent atelectasis & 1 & 59 & 60 \\
\hline 3-6 months & 0 & & 0 & & 60 & 60 \\
\hline Total & 11 & & 20 & & 29 & 60 \\
\hline
\end{tabular}

Uni-variate analysis of follow-up did not reveal difference between the factors studied;they were the localization on the lung (left or right), the size of the cyst, the nature of the cyst (intact or ruptured), and the presence of infection (Table IV).

Table IV. Uni-variate analysis of the complications according to the localization of the cysts, the nature of the cysts, the

\begin{tabular}{lccc}
\multicolumn{4}{c}{ presence of infection, and the size of the cysts. } \\
\cline { 1 - 2 } & $\begin{array}{c}\text { Complications } \\
\mathrm{n}(\%)\end{array}$ & $\begin{array}{c}\text { No complications } \\
\mathrm{n}(\%)\end{array}$ & $\mathrm{p}$ \\
\cline { 1 - 2 } $\begin{array}{l}\text { Pulmonary localization } \\
\text {-Right }\end{array}$ & $7 / 34(21 \%)$ & $27 / 34(79 \%)$ & \\
$\quad$-Left & $4 / 24(15 \%)$ & $22 / 26(85 \%)$ & 0.43 \\
$\begin{array}{l}\text { Nature of the cyst } \\
\text {-Intact }\end{array}$ & $4 / 28(14 \%)$ & $24 / 28(86 \%)$ & 0.33 \\
-Ruptured & $7 / 32(22 \%)$ & $25 / 32(78 \%)$ & \\
$\begin{array}{l}\text { Infection } \\
\text {-Yes }\end{array}$ & $6 / 36(17 \%)$ & $30 / 36(83 \%)$ & 0.46 \\
$\quad$-No & $5 / 24(21 \%)$ & $19 / 24(79 \%)$ & \\
$\begin{array}{l}\text { Size of the cyst } \\
<10 \mathrm{~cm}\end{array}$ & & \\
$\geq 10 \mathrm{~cm}$ & $6 / 44(14 \%)$ & $38 / 44(86 \%)$ & 0.12 \\
\hline
\end{tabular}

\section{DISCUSSION}

Our study finds no mortality of the conservative approaches for pulmonary hydatid cysts, morbidity was at $18 \%$, and no recurrence was observed after a median follow-up of 15 months (range 3-46 months). The main technique used in our practice is cystectomy with closure of bronchial opening and capitonage, it was performed to treat $71 / 73$ cysts (97\%), for the two other cysts, it was pericystectomy and wedge resection because of the small size and the peripheral situation of the cysts. A meta-analysis of 14 reports and 4255 patients with pulmonary hydatid cyst undergoing surgical intervention reveals a mortality rate of $1.45 \%$ with excellent cure rate, morbidity ranges from 0 to $17 \%$

among 3433 patients [6]. Our results are good and support the notion that surgery whenever possible provides not only an excellent cure rates but is also safe, no recurrence are seen on the follow-up, knowing that $43 \%$ of the patients were treated by albendazole in the postoperative.

Various surgical procedures for pulmonary hydatid cysts are described in the literature, the conservative approaches consists globally the most techniques used, it includes enucleation, pericystectomy, cystectomy with capitonage (Barret's method), cystectomy with closure of the bronchial opening and capitonage (Posadas method), cystectomy with closure of bronchial opening alone, and open aspiration by Figuera technique [5]. In this study, the right lower lobes were the mainly affected area of the lung $(38.3 \%)$ and the left lower lobes were affected at $33.3 \%$. Our study is similar to what described Achir et al. [7], Ulku and al. [4] and Sehitogullari and al. [8] who showed that the right lower lobe was the most affected area of the lung. Contrary to the results reported bySadrizadeh and al. where the left lower lobewas more frequently affected [3].

Our series is characterized by the percentage of the giant cysts $(27 \%)$ with a median size of $13 \mathrm{~cm}$; giant 
cysts are defined by a size greater than $10 \mathrm{~cm}$, This parameter did not constitute a limit to perform conservative approachpreserving pulmonary parenchyma in our surgical practice. Usluer O. et al. find $14 \%$ of the giant cysts in a series of 537 patients, they compared two groups of patients with pulmonary hydatid cysts, those with size less than $10 \mathrm{~cm}$ (group A) $(\mathrm{n}=462)$ and those with size greater than $10 \mathrm{~cm}$ (group B) $(n=75)$. The authors showed that the size did not appear to influence short-term peri-operative outcome, and that lobectomy rates were significantly higher in-group B (4\%), compared with group A [9]. In our series, we did not perform lobar resection, the giant cysts were mainly localized in the lower lobes, conservative approaches were sufficient to perform the excision of the parasite, the long-term follow-up did not reveal any complications. The decision of the lobectomy is taken habitually at the time of surgery; in our cases, we have judged that the residual parenchyma was in good condition with efficient ventilation after cystectomy.

Usluer $\mathrm{O}$ et al. [9] reported that the percentages of cysts that caused parenchymal damage were $4 \%$ in giant cysts and $1 \%$ in normal-sized cysts, and even though giant cysts in here series were statistically more likely to require anatomic lung resection, the authors were able to perform parenchyma-sparing operations in the overwhelming majority of cases (96\%). Sokouti M. et al compared the giant and the non-giant cysts between 612 patients, they reported that lobectomy was significantly higher and was performed in 66\% from the giant cysts (39/59) and in $1.3 \%(7 / 553)$ from the non-giant cysts [10]. Kocer et al. reported no difference in surgical procedures between the giant and non-giant groups [11]. Sadrizadeh A. et al in studying 87 patients, reported no significant relation between the size and number of cysts and lobectomy necessity. The giant cysts represented in this series $29.9 \%$, and there was a significant relation between the occurrence of cyst in middle lobe and lobectomy necessity [3]. The parenchymal damage may be due to the great size of the cyst, and by the chronic infections caused by the complicated cysts by bronchial rupture. The comparison according the location, the nature and the size of cyst, and the presence of infection did not show difference between the patients according to their postoperative outcomes in our series. However, selection bias could play a role in these results. In our series, only three times who the middle lobe was affected, the majority of the disease was located on the lower lobes that have greatest size on the lungs with a different bronchial distribution than the upper lobes, and the exact localization of the cysts (central or peripheral) has not been specified.
In a review of cystic pulmonary hydatidosis [1], Sarkar M. et al. reported that the main indication of lobectomy include cysts involving more than $50 \%$ of the lobe, cysts with severe pulmonary suppuration not responding to treatment, multiple unilobar cysts, and sequelae of hydatid disease such as bronchiectasis, pulmonary fibrosis, or severe hemorrhage. The rate of lobectomy is reported at $0.5-45 \%$ in previous studies [11-16]. We believe that several parameters play a role in the decision of the lobectomy. Its include size, localization on the lung, localization on the lobe (peripheral or central), number of the cysts, degree of the bronchial fistulas, and degree of the parenchymal damage, as well as the effectiveness of lobe ventilation after a first conservative approach with bronchial closure. Our approach and results were similar that reported by Aldahmashi $M$ et al. [17], cystectomy and capitonnage was the conservative surgical methods of choice in treating 148 cases of pulmonary hydatid cysts with $35.14 \%$ of the giant cysts. Hasdiraz L et al. [18]in a series of 107 consecutive surgery for pulmonary hydatid cysts, none of the patients required lobectomy.

Several minor radiological anomalies can appeared in chest-x ray after the capitonnage, this shadow represents sutured lung tissue. In studying the long term follow-up of the patients and regarding evolution of the radiological aspects up to 3 months, we found that the anomalies disappears gradually and no complications appeared. It can be minor atelectasis, pleural effusion, or radi-opaque opacity without serious consequences. Aldahmashi $\mathrm{M}$ et al. reported the same observations regarding the disappearance of the radio-opaque shadow in the postoperative after capitonnage within 3 weeks to 3 months [17].

None of the patients required lobectomy; this decision must be taken carefully, even in the infected cases, atelectasis, giant cysts and multiple cysts in the same lobe. The chance for the parenchyma to make up the residual cavity is done gradually provided a regular post-operative kinesitherapy and a well-conducted medical treatment.

Our study has some limits, first the retrospective nature, secondly some bias regarding the exact localizations, and some parameters have not been specified, like the exact localizations on the lobe, the number and the type of fistulas closed. Otherwise, our practice in surgery of the pulmonary hydatidosis, and our results suggested that the parenchymal preservation by cystectomy with capitonnage remains a valid surgical method for pulmonary hydatid cystsdespite the largest and complicated cysts, with excellent surgical results and accepted complications. In addition, further 
studies are needed to define exactly the limits between the conservative approaches and the pulmonary resection in the surgery of the pulmonary hydatid cysts.

\section{CONFLICT OF INTEREST:}

The authors declare no conflict of interest.

\section{REFERENCES}

1. Sarkar M, Pathania R, Jhobta A, Thakur BR, Chorpa R. Cystic pulmonary hydatidosis. Lung India 2016;33:179-191

2. Y. Cherradi, R. Afifi, W. Khannoussi, M. Firwana, A. Rahaoui, M. Benazouz and all. Long terpe results of rcutaneous management of liver hydatid cysts: experience of university hospital in endemic region. Journal of Medical and Surgical Research(J.Med.Sur.Res.) 2016;3 (2):275-281

3. Sadrizadeh A, Haghi SZ, Masuom SHF, Bagheri R, Dalouee MN. Evaluation of the effect of pulmonary hydatid cyst location on the surgical technique approaches. Lung India 2014;31 (4):361-365

4. Ulku R, Yilmaz HG, Onat S, Ozcelik C. Surgical treatment of pulmonary hydatid cysts: reports of 139 cases. International Surgery 2006;91(2):77-81

5. Nabi MS, Waseem T. Pulmonary hydatid disease: what is the optimal surgical strategy? International Journal of Surgery 2010;8:612-616

6. Athanassiadi K, Kalavrouziotis G, Loutsidis A, Bellenis I, Exarchos N. Surgical treatment of echinococcosis by a transthoracic approach: a review of 85 cases. Eur J CardiothoracSurg 1998;14:134-140

7. Achir A, Ouadnouni Y, Smahi M, Bouchikh M, Msougar Y, Lakranbi M, Benosman A. pulmonary hydatidosis. Maroc Médical 2006; 28(4):228-235

8. Sehitogullari A. Our results in surgical treatment of hydatid cyst of the lungs. Eur J Gen Med 2007;4:58

9. Usluer O, Ceylan KC, Kaya S, Sevinc S, Gursoy S. Surgical management of pulmonary hydatid cysts: is size an important prognostic indicator? Tex Heart Inst J.2010;37(4):429-434

10. Sokouti M, Pezeshkian M, Ghabili K, Golzari S. Surgical procedures and postoperative complications in patients with giant and non-giant pulmonary hydatid cysts. Life Science J 2013;10(1): 138-142

11. Kocer B, Gulbahar G, Han S, Durukan E, Dural K, Sakinci U. An analysis of clinical features of pulmonary giant hydatid cyst in adult population. Am J Surg 2009;197:177-181

12. Kabiri el-H, Caidi M, al Aziz S et al. Surgical treatment ofhydatidothorax. Series of 79 cases. ActaChir. Belg. 2003;103:401-404

13. Kabiri el H, Traibi A, El Hammoumi M, El Oueriachi F, Arsalane A. Parenchyma sparing procedures is possible for most pulmonary hydatid disease without recurrence and low complications.Med Arch. 2012;66(5):332-335
14. Isitmangil $\mathrm{T}$, Sebit $\mathrm{S}$, Tunc $\mathrm{H}$ et al. Clinical experience of surgical therapy in 207 patients with thoracic hydatidosis over a 12-year-period. Swiss Med. Wkly. 2002;132: 548-552

15. Dakak M, Genc O, Gurkok $S$ et al. Surgical treatment for pulmonary hydatidosis (a review of 422 cases). J. R. Coll. Surg.Edinb. 2002;47: 689692

16. Yena S, Sanogo ZZ, Keita A et al. Surgery for pulmonary hydatidcyst in Mali. Ann. Chir. 2002; 127: $350-355$

17. Aldahmashi M, Alassal M, Kasb I, Elrakhawy H. Conservative surgical management for pulmonary hydatid cyst: analysis and outcome of 148 cases. Can Respir J. 2016;2016:8473070.

18. Hasdiraz L, Oguzkaya F, Bilgin M. Is lobectomy necessary in the treatment of pulmonary hydatid cysts? ANZ J. Surg. 2006;76:488-490 